\title{
Safe sleep practices in a New Zealand community and development of a Sudden Unexpected Death in Infancy (SUDI) risk assessment instrument
}

\author{
Barbara C Galland ${ }^{1 *}$, Andrew Gray², Rachel M Sayers', Anne-Louise M Heath³ ${ }^{3}$ Julie Lawrence ${ }^{1}$, Rachael Taylor ${ }^{4}$ \\ and Barry J Taylor ${ }^{1}$
}

\begin{abstract}
Background: Interventions to prevent sudden unexpected death in infancy (SUDI) have generally been population wide interventions instituted after case-control studies identified specific childcare practices associated with sudden death. While successful overall, in New Zealand (NZ), the rates are still relatively high by international comparison. This study aims to describe childcare practices related to SUDI prevention messages in a New Zealand community, and to develop and explore the utility of a risk assessment instrument based on international guidelines and evidence.

Methods: Prospective longitudinal study of 209 infants recruited antenatally. Participant characteristics and infant care data were collected by questionnaire at: baseline (third trimester), and monthly from infant age 3 weeks through 23 weeks. Published meta-analyses data were used to estimate individual risk ratios for 6 important SUDI risk factors which, when combined, yielded a "SUDI risk score".

Results: Most infants were at low risk for SUDI with $72 \%$ at the lowest or slightly elevated risk (combined risk ratio s1.5). There was a high prevalence of the safe practices: supine sleeping (86-89\% over 3-19 weeks), mother not smoking (90-92\% over 3-19 weeks), and not bed sharing at a young age ( $87 \%$ at 3 weeks). Five independent predictors of a high SUDI risk score were: higher parity $(P=0.028)$, younger age $(P=0.030)$, not working or caring for other children antenatally $(P=0.031)$, higher depression scores antenatally $(P=0.036)$, and lower education $(P=0.042)$.

Conclusions: Groups within the community identified as priorities for education about safe sleep practices beyond standard care are mothers who are young, have high parity, low educational levels, and have symptoms of depression antenatally. These findings emphasize the importance of addressing maternal depression as a modifiable risk factor in pregnancy.
\end{abstract}

Keywords: Bed sharing, Breastfeeding, Environmental risk factors, Maternal depression, Prone sleeping, SIDS, Parental smoking

\section{Background}

Sudden unexpected death in infancy (SUDI) is a broad term used for all sudden unexpected infant deaths ranging from those that remain unexplained after a full investigation (unexplained SUDI) to those where a full explanation of the death is found during subsequent investigations (explained SUDI). Sudden infant death syndrome (SIDS) and "cot death" have previously been used to describe the

\footnotetext{
*Correspondence: barbara.galland@otago.ac.nz

'Department of Women's \& Children's Health, University of Otago, Dunedin, New Zealand

Full list of author information is available at the end of the article
}

"unexplained SUDI" group where SIDS is defined as "the sudden and unexpected death of an infant under 1 year of age, with onset of the lethal episode apparently occurring during sleep, that remains unexplained after a thorough investigation including performance of a complete autopsy, and review of the circumstances of death and the clinical history" [1]. In developed countries, unexplained SUDI represents the highest proportion of all post-neonatal deaths [2].

In the late 1980s and early 1990s, education programs and campaigns, commonly referred to as the "Back to Sleep" campaigns, were started after several risk factors 
for SIDS were discovered, most importantly prone (front) sleeping, smoking, bed sharing (particularly in the presence of maternal smoking), and not breastfeeding. These programs were followed by a dramatic decline in unexplained SUDI $[3,4]$ supporting the idea that such risk factors might be causally related [5]. In New Zealand (NZ), rates of unexplained SUDI have continued to decline, but have always been relatively high compared to other countries [6]. The unexplained SUDI rates per 1000 live births amongst Māori (the indigenous people of NZ) have been 5 times that of non-Māori [7]. However a recent decline in unexplained SUDI and among Māori in NZ has been reported [8], the reasons for which remain to be determined.

The first aim of this study was to determine the extent to which infant care practices for prevention of SUDI are being followed in a NZ community, as much of what is known about trends in practices linked to SUDI reduction in NZ has been derived from surveys conducted in the 1990s and early 2000s. The second aim was to develop a SUDI risk assessment instrument that could be used to identify maternal, infant and household variables predictive of SUDI risk. Such a risk score could be used in identifying cases where additional support for families is needed and might indicate useful points for interventions to target, as well as facilitating comparisons between communities and within communities over time.

\section{Methods}

Information was collected about the infant care practices of 209 Dunedin, NZ, parents of infants born between June 2009 and February 2011. Participants were families comprising the control group ( $n=209$ ) of a 4-arm randomized controlled trial (RCT): the Prevention of Overweight in Infancy (POI) study (total $n=802$ ). Parents were recruited antenatally from the single maternity hospital servicing Dunedin city. Infants were excluded if they lived outside the study area, were born before full term (36.5 weeks), or if a congenital abnormality or a physical or intellectual disability likely to affect feeding, physical activity or growth was identified. In total, 1458 of 2946 women were eligible to participate in the RCT. After declines ( $\mathrm{n}=511$ ) and post-birth exclusions ( $\mathrm{n}=45), 802$ enrolled in the main trial (58\% response rate). However only data from the control group $(n=209)$ were included here because the intervention arms received education and support on infant sleep and/or breastfeeding. Thus the control group received standard care, whereas the 3 intervention groups received 1) breastfeeding, activity and complementary feeding education and support, 2) infant sleep education, or 3) both interventions. The RCT study details including group allocation methods have been published [9]. The New Zealand Lower South Regional Ethics Committee approved the study (Project Key: LRS/08/12/ 063) and all participants gave written informed consent.

\section{Information for parents on safe sleep}

All NZ families receive information about infant safe sleep practices via the standard care offered free and delivered by registered Well Child providers, during home or clinic visits typically scheduled at ages 6 weeks, and 3 and 5 months. A range of issues, including safe sleep are covered at these sessions and Well Child providers are required to provide proof to the NZ Ministry of Health that such issues have been discussed [10]. Midwives, handing over care to Well Child providers at 6 weeks, also follow Ministry guidelines in regard to informing parents about infant safe sleep practices. In addition, written materials on helping protect babies against SUDI are given to parents at antenatal and postnatal visits.

\section{Data collection}

At baseline (third trimester) and monthly at infant ages 3 weeks through 23 weeks, parents completed questionnaires collecting data on the variables to be used to calculate the SUDI risk score: sleep position, place of sleep, smoking, breastfeeding, and pacifier use. Questions were also asked about bedding (under and over baby). The questionnaires were administered in person at baseline, 3 and 19 weeks (full questionnaires), and by telephone at 7, 11, 15 and 23 weeks (using a subset of questions to minimize participant burden). Additional data collected at baseline were: demographic information, pre-pregnancy body mass index (BMI), maternal depression (using the 10-item Edinburgh Postnatal Depression Scale (EPDS) [11] validated for use in the prenatal period [12]), mother's report of parenting stress (using the attachment and adaptability sub-scales from the Parenting Stress Index (PSI) [13]), and maternal alcohol consumption via a brief screening 3-question test for heavy drinking and active alcohol abuse or dependence, the Alcohol Use Disorders Identification Test (AUDIT-C) [14]. The NZ Deprivation Index (NZDep2006) [15] was used as an index of neighborhood deprivation based on the participant's address at baseline. The index range is 1 to 10 , with 1 representing areas of least deprivation, and 10, areas of highest deprivation. Infant birth characteristics were collected from hospital records following birth.

\section{Development of the SUDI risk assessment instrument}

Five key "best practice" variables were identified (sleeping supine, not smoking during pregnancy, not bed sharing, breastfeeding and using a pacifier) based on NZ and international guidelines and research on SUDI prevention. Estimated risk ratios (with odds ratios used to approximate these given the low prevalence of SUDI) were extracted from the literature for not following each "best practice": sleep supine (back) [16], not smoking during pregnancy [17], not bed sharing (calculating separate risks for those who smoked and those who did not) [18], 
breastfeeding (any) [19], and using a pacifier [20]. The last of these is not currently part of NZ guidelines around SUDI prevention. The SUDI risk scores were calculated for each family in the study, using data collected at the age when each "best practice" was most relevant. We then created a total risk score for participants by multiplying these risk ratios together if they were not following one or more of the best practice recommendations. For example, an infant sleeping prone was given an OR of 6.91 for this practice [16]. If the same infant had a mother who smoked during pregnancy, but did not bed share, an OR of 1.98 [18] was also given. The risk ratio (relative risk) for the infant was then calculated at 13.7, i.e. the product of the odds ratios for the two practices. An estimated risk ratio of 1 is the reference value (all best practice). Adjusted odds ratios were used where possible but were not available for prone/side sleep position or for breastfeeding.

\section{Statistical analysis}

Appropriate summary statistics for sleep practices of interest and the SUDI risk scores are presented. The numbers of participants contributing to each variable of interest are described within the Tables. Cases with missing data for a particular variable were omitted for the unadjusted and any adjusted analyses involving that variable. Ethnicity was prioritized in order of Māori, Pacific, Asian, Other, and finally European. This order of prioritization follows national recording standards used when a participant responds with more than one ethnicity. Infant ethnicity was based on further prioritizing both maternal and partner ethnicity using the same ordering. SUDI risk scores were calculated as described earlier. Linear regression was used to explore predictors of SUDI risk scores. Unadjusted models were developed for the following variables relating to the mother: age, prioritized ethnicity (in order of Māori, Other, European), education, self-reported pre-pregnancy BMI, parity, EPDS scores [11], PSI scores [13], and AUDIT-C scores [14]; relating to the household: NZDep2006 [15] and family income; and relating to the infant: gestational age and sex. Variables with unadjusted $P<0.25$ were included in a final adjusted model. Fractional polynomials were used to investigate, and where present, model non-linear associations. Standard model diagnostics were investigated including normality and homoscedasticity of residuals. A log-transformation for the risk score was used to reduce skew and heteroscedasticity in model residuals and so effects are shown as ratios of geometric means, alongside $95 \% \mathrm{CIs}$, and $P$ values. All analyses were conducted using Stata 13.1 (StataCorp. 2013. Stata Statistical Software: Release 13. College Station, TX: StataCorp LP) and two-sided $P<0.05$ was considered statistically significant.

\section{Results}

Table 1 summarizes the maternal, infant, and household characteristics. The majority of infants were classified as European (77.5\%) or Māori (11.5\%). Approximately 70\% of mothers had received a post-secondary education, 93\% lived with the infant's father/partner and $45 \%$ of families lived in neighborhoods within the mid-range of the deprivation index (NZDep deciles 4-7). Family income was not reported by $8 \%$, but of those remaining, $44 \%$ received more than the average household income for the region at the time of the study.

\section{Infant care practices, breastfeeding and parental smoking} The safest sleep position, supine (back), was highly prevalent with $86 \%$ and $90 \%$ of infants sleeping in this position at 3 and 19 weeks respectively. Only $2.0 \%$ and $2.1 \%$ chose to sleep their baby prone (front) at 3 and 19 weeks respectively. Figure 1 shows the changes in sleep location from infant age 3 weeks to 19 weeks. Thirteen percent of participants reported bed sharing at 3 weeks of age, reducing by almost half to $7.5 \%$ at 7 weeks and $5.6 \%$ at 19 weeks of age. Room sharing in a cot or bassinette at 3 weeks was the most common practice (68\%), transitioning to infant sleeping in a separate room over time.

At approximately 2 months of age, $89 \%$ of infants were receiving at least some breast milk. The majority (71\%) of those being breastfed at that age were breastfed exclusively. No specific education is given about pacifier use in NZ but we include it here because it is a safe sleep message adopted by other countries. Within our cohort, pacifier use was relatively uncommon with $10 \%$ of infants using a pacifier daily at 3 weeks rising to $17 \%, 18 \%$, $19 \%, 19 \%$ and $19 \%$ at $7,11,15,19$ and 23 weeks respectively. Eight percent and 10\% of mothers were smokers (current or daily) in the third trimester of pregnancy, and at infant age of 19 weeks, respectively.

Of additional interest is the finding that $18 \%$ of partners were smokers in the third trimester of pregnancy, and a similar figure at an infant age of 19 weeks. The prevalence of smoking in the car was low (mothers 2.5\% and $1.1 \%$ during pregnancy and at infant age 19 weeks respectively, and partners, $2.3 \%$ and $6.6 \%$ respectively) as was smoking inside the home. Another practice that is discouraged, but that was not included in the SUDI risk score, was using a sheepskin as a soft surface under bedding, which was used by $10 \%$ of families. The use of plastic wrapping under the bedding was uncommon at $4.2 \%$.

\section{Best practice and the SUDI risk ratio assessment}

Best practice variables related to SUDI prevention, and the data source and odds ratios (95\% CIs) for individual risks are given in Table 2. In our sample, best practices predominated for all risk factors excluding pacifier use. For example, supine sleeping was practiced by $90 \%$, any 
Table 1 Maternal, family, and infant characteristics

\begin{tabular}{|c|c|c|c|}
\hline & Total (n) & n (\%) & Mean (SD) \\
\hline Maternal age at birth (years) & 209 & - & $31.5(5.0)$ \\
\hline Maternal prioritized ethnicity & 209 & - & - \\
\hline European & - & $177(84.7)$ & - \\
\hline Māori & - & $15(7.2)$ & - \\
\hline Other ${ }^{\mathrm{c}}$ & - & $17(8.2)$ & - \\
\hline $\begin{array}{l}\text { Maternal BMI (pre-pregnancy) } \\
\text { categories }\end{array}$ & 207 & - & - \\
\hline Underweight & - & $9(4.4)$ & - \\
\hline Healthy & - & $113(54.6)$ & - \\
\hline Overweight & - & $57(27.5)$ & - \\
\hline Obese & - & $28(13.5)$ & - \\
\hline Maternal education & 206 & - & - \\
\hline Year 11 or lower & - & $14(6.8)$ & - \\
\hline Year 12 or 13 & - & $41(19.9)$ & - \\
\hline Post-secondary & - & $29(14.1)$ & - \\
\hline Degree or higher & - & $122(59.2)$ & - \\
\hline Maternal employment & 209 & - & - \\
\hline $\begin{array}{l}\text { Working (full-time, part-time, } \\
\text { or casual) }\end{array}$ & - & $120(57.4)$ & - \\
\hline Maternity leave (paid or unpaid) & - & $33(15.8)$ & - \\
\hline Student (and possibly working) & - & $7(3.4)$ & - \\
\hline Not working (includes carers) & - & $49(23.4)$ & - \\
\hline Parity & 209 & - & $2(1)^{a}$ \\
\hline Maternal EPDS & 208 & - & $6.8(4)$ \\
\hline Maternal stress & 207 & - & $12.7(3.4)$ \\
\hline Maternal AUDIT-C & 162 & - & $0(1)$ \\
\hline Living arrangements & 208 & - & - \\
\hline With child's father/partner & - & $193(92.8)$ & - \\
\hline With family & - & $10(4.8)$ & - \\
\hline Other & - & $5(2.4)$ & - \\
\hline NZDep2006 & 206 & - & - \\
\hline 1-3 (low deprivation) & - & $74(35.9)$ & - \\
\hline $4-7$ & - & $93(45.2)$ & - \\
\hline 8-10 (high deprivation) & - & $39(18.9)$ & - \\
\hline Family income (NZDd) & 209 & - & - \\
\hline$\leq \$ 30,000$ & - & $20(9.6)$ & - \\
\hline$-\$ 70,000$ & - & $80(38.3)$ & - \\
\hline Over $\$ 70,000$ & - & $92(44.0)$ & - \\
\hline Not provided & - & $17(8.1)$ & - \\
\hline Gestation (weeks) & 209 & - & $40.0(1.3)$ \\
\hline Birth weight (g) & 207 & - & $3522(484)$ \\
\hline Infant sex (M:F) & 209 & $0.88^{b}$ & - \\
\hline
\end{tabular}

Table 1 Maternal, family, and infant characteristics (Continued)

\begin{tabular}{clll}
\hline Infant prioritised ethnicity & 209 & - & - \\
European & - & $162(77.5)$ & - \\
Māori & - & $24(11.5)$ & - \\
Other $^{c}$ & - & $23(11.0)$ & - \\
\hline
\end{tabular}

amedian (IQR).

bratio.

'Other includes Pacific, Asian, Middle Eastern, Latin American, African.

${ }^{\mathrm{d} N Z D}$, New Zealand dollars. $\$ 70,000$ represents average annual household income in region.

Unless otherwise stated, maternal and family data were collected at baseline (third trimester).

breastfeeding by $89 \%$, and not bed sharing in combination with no maternal smoking by $81 \%$. As only 1 mother smoked during pregnancy and bed shared with her infant, the prevalence of this risk factor in our sample was less than $0.5 \%$. Consequently, risky practices were low. The only (internationally) recommended practice that few parents followed was regular use of a pacifier (19\%).

The SUDI risk score could range from a possible 1.0 (avoiding all risk factors) to 160.6 (with all risk factors present). The arithmetic mean score in this study was 3.1 with a median of 1.4 (values ranged from 1.0-61.0). The frequency distribution was as follows: 20 infants (11\%) had minimum risk with an $\mathrm{OR}=1.0 ; 106$ infants (60\%) had an OR of $>1$ to $\leq 1.5 ; 28$ infants (16\%) had an OR of $>1.5$ to $\leq 3$; 13 infants $(7.4 \%)$ had an OR of $>3$ to $\leq 10 ; 7$ infants $(4.0 \%)$ had an OR of $>10$ to $\leq 20 ; 2$ infants $(1.1 \%)$ had an OR of $>20$.

\section{Predictors of high SUDI risk scores}

Fourteen maternal, infant and household variables were explored as potential predictors of SUDI risk scores (Table 3). The unadjusted models yielded 9 predictors for further analysis $(P<0.25)$ with statistically significantly greater risk suggested for low maternal age, low maternal education, maternal non-working status, high EPDS score, low family income, high parity and statistically non-significant results for ethnicity (maternal), maternal stress, and infant sex. The final adjusted model found 5 statistically significant predictors, i.e. higher risk scores were associated with mothers who had a higher number of previous births $(P=0.028)$, were younger $(P=0.030)$, were unemployed or not caring for other children at baseline $(P=0.031)$, had higher EPDS depression scores at baseline $(P=0.036)$, and were less educated $(P=0.042)$. Māori ethnicity was not a statistically significant independent predictor for a high SUDI Risk Ratio Score $(P=0.659)$ after being almost statistically significant $(P=0.053)$ in its unadjusted model. 


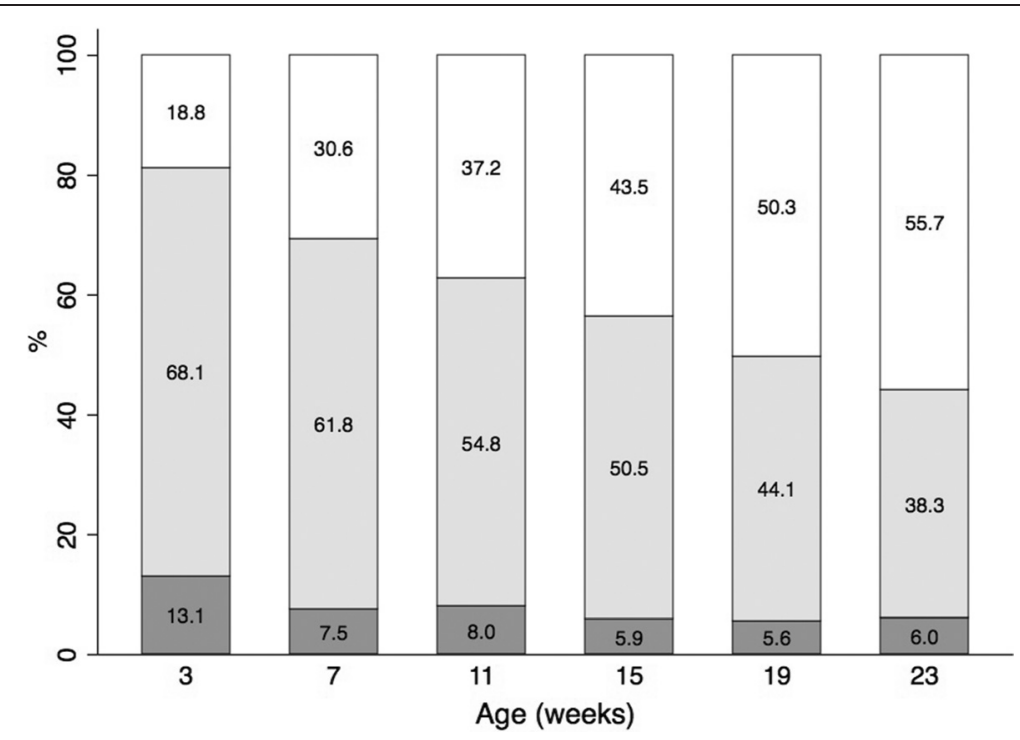

Figure 1 Change in infant nighttime sleep location from 3 to 23 weeks. Percentage of infants bed sharing (dark shading), room sharing (light shading), and sleeping in their own room (white).

\section{Discussion}

The present study demonstrates that the main safe sleep messages for SUDI prevention are highly practiced within this NZ community sample. Risk scores calculated for our population confirmed that the majority $(72 \%)$ were at either the lowest or slightly elevated risk (SUDI Risk Ratio Score $\leq 1.5$ ) for SUDI through safe sleep and feeding practices. Importantly, this score identified 5 predictors of SUDI risk related to the mother: young maternal age, low education, not employed in the third trimester of pregnancy, high parity, and high depression scores antenatally. Most of these factors would be expected, but are difficult to modify. However, the increased SUDI risk score amongst mothers with high depression scores on the EPDS antenatally is of particular interest, given the strong association between antenatal and postnatal depression [21], the adverse consequences of depression for quality maternal-infant interactions (reviewed in [22]), and the reported association of postnatal depression with SUDI [23]. Although there is a high degree of health surveillance antenatally in NZ, screening for maternal depression is not routine.

The SUDI risk assessment instrument is, as far as we are aware, unique within the SUDI literature in that it

Table 2 Data source for SUDI Risk score and the number of infants in this study following best practice

\begin{tabular}{|c|c|c|c|c|c|c|c|}
\hline \multirow{3}{*}{ Best practice } & \multirow{3}{*}{ Risk factor } & \multirow{3}{*}{ Data source } & \multicolumn{5}{|l|}{ Current study } \\
\hline & & & \multirow[t]{2}{*}{$\begin{array}{l}\text { Risk score odds } \\
\text { ratio ( } 95 \% \text { C.I.) }\end{array}$} & \multirow[t]{2}{*}{ Age (weeks) } & \multirow[t]{2}{*}{$\mathbf{n}$} & \multicolumn{2}{|c|}{$\begin{array}{l}\text { Following } \\
\text { best practice, } n(\%)\end{array}$} \\
\hline & & & & & & Yes & No \\
\hline Supine sleep position & Prone or side sleep position & Gilbert et al., 2005 [16] & $6.91(4.63-10.32)$ & 19 & 195 & $176(90.3)$ & $19(9.7)$ \\
\hline Any breastfeeding & No breastfeeding & Hauck et al., 2011 [19] & $2.63(1.85-3.7)^{\mathrm{a}}$ & 8.7 & 199 & $178(89.4)$ & $21(10.6)$ \\
\hline Usual pacifier use & No pacifier use & Hauck et al., 2005 [20] & $1.41(1.12-1.69)^{b}$ & 19 & 194 & $36(18.6)$ & $158(81.4)$ \\
\hline \multirow{4}{*}{$\begin{array}{l}\text { No bed sharing \& } \\
\text { No maternal smoking } \\
\text { in pregnancy }\end{array}$} & & & & 3 & 191 & $154(80.6)$ & $37(19.4)$ \\
\hline & $\begin{array}{l}\text { No bed sharing \& Maternal } \\
\text { smoking in pregnancy }\end{array}$ & Carpenter et al., 2004 [17] & $1.98^{\mathrm{b}^{*}}$ & - & - & - & $12(6.3)$ \\
\hline & $\begin{array}{l}\text { Bed sharing \& No maternal } \\
\text { smoking in pregnancy }\end{array}$ & Vennemann et al., 2012 [18] & $1.66(0.91-3.01)^{b}$ & - & - & - & $24(12.6)$ \\
\hline & $\begin{array}{l}\text { Bed sharing \& Maternal } \\
\text { smoking in pregnancy }\end{array}$ & Vennemann et al., 2012 [18] & $6.27(3.94-9.99)^{b}$ & - & - & - & $1(0.5)$ \\
\hline
\end{tabular}


Table 3 Predictors of SUDI risk scores

\begin{tabular}{|c|c|c|c|c|c|c|c|}
\hline \multirow[t]{2}{*}{ Predictor } & \multirow[b]{2}{*}{$\mathbf{n}$} & \multicolumn{3}{|l|}{ Unadjusted } & \multicolumn{3}{|l|}{ Adjusted $^{a}(n=170)$} \\
\hline & & Ratio of geometric means & $95 \% \mathrm{Cl}$ & $P$-value & Ratio of geometric means & $95 \% \mathrm{Cl}$ & $P$-value \\
\hline Maternal age at birth (years) & 176 & - & - & - & - & - & - \\
\hline $\begin{array}{l}\text { Fractional polynomial } \\
\text { transformed predictors }\end{array}$ & - & - & - & $<0.001$ & - & - & - \\
\hline 20 & - & 1.00 & - & - & - & - & - \\
\hline 25 & - & 0.23 & $0.12-0.44$ & - & - & - & - \\
\hline 30 & - & 0.16 & $0.07-0.34$ & - & - & - & - \\
\hline 35 & - & 0.16 & $0.08-0.33$ & - & - & - & - \\
\hline 40 & - & 0.17 & $0.09-0.34$ & - & - & - & - \\
\hline Linear predictor & - & - & - & - & 0.97 & $0.95-1.00$ & 0.030 \\
\hline Maternal prioritized ethnicity & 176 & - & - & 0.053 & - & - & 0.649 \\
\hline European & - & 1.00 & - & - & 1.00 & - & - \\
\hline Māori & - & 1.79 & $1.12-2.88$ & - & 1.21 & $0.75-1.95$ & - \\
\hline Other & - & 0.98 & $0.67-1.43$ & - & 0.92 & $0.64-1.32$ & - \\
\hline Maternal BMI pre-pregnancy (per unit) & 174 & 1.01 & $0.99-1.03$ & 0.297 & - & - & - \\
\hline Maternal education & 173 & - & - & $<0.001$ & - & - & 0.042 \\
\hline Year 11 or lower & - & 1.00 & - & - & 1.00 & - & - \\
\hline Year 12 or 13 & - & 0.50 & $0.31-0.80$ & - & 0.61 & $0.37-1.00$ & - \\
\hline Post-secondary & - & 0.39 & $0.23-0.64$ & - & 0.52 & $0.31-0.87$ & - \\
\hline Degree or higher & - & 0.33 & $0.21-0.51$ & - & 0.52 & $0.33-0.83$ & - \\
\hline Maternal employment & 176 & - & - & 0.001 & - & - & 0.031 \\
\hline Not working & - & 1.00 & - & - & 1.00 & - & - \\
\hline Full-time, part-time, casual & - & 0.64 & $0.52-0.79$ & - & 0.79 & $0.64-0.98$ & - \\
\hline Parity (per birth) & 176 & 1.15 & $1.05-1.27$ & 0.004 & 1.13 & $1.01-1.26$ & 0.028 \\
\hline EPDS (per point) & 175 & 1.06 & $1.03-1.09$ & $<0.001$ & 1.03 & $1.00-1.06$ & 0.036 \\
\hline Stress (per point) & 175 & 1.02 & $0.99-1.06$ & 0.177 & 1.01 & $0.98-1.05$ & 0.353 \\
\hline AUDIT-C (per point) & 140 & 0.97 & $0.84-1.11$ & 0.657 & - & - & - \\
\hline Living arrangements & 176 & - & - & 0.697 & - & - & - \\
\hline Without partner or family & - & 1.00 & - & - & - & - & - \\
\hline With partner & - & 1.35 & $0.57-3.19$ & - & - & - & - \\
\hline With family & - & 1.55 & $0.56-4.28$ & - & - & - & - \\
\hline NZDep2006 (per decile) & 173 & 1.02 & $0.97-1.06$ & 0.489 & - & - & - \\
\hline Family income $\left(N Z D^{b}\right)$ & 176 & - & - & $<0.001$ & - & - & 0.062 \\
\hline$\leq \$ 30,000$ & - & 1.00 & - & - & 1.00 & - & - \\
\hline$-\$ 70,000$ & - & 0.93 & $0.62-1.39$ & - & 0.94 & $0.63-1.41$ & - \\
\hline Over $\$ 70,000$ & - & 0.62 & $0.41-0.92$ & - & 0.77 & $0.51-1.17$ & - \\
\hline Not provided & - & 1.39 & $0.81-2.37$ & - & 1.38 & $0.80-2.38$ & - \\
\hline Gestation (per week) & 176 & 0.98 & $0.90-1.07$ & 0.708 & - & - & - \\
\hline Infant sex & 176 & - & - & 0.246 & - & - & 0.283 \\
\hline Girl & - & 1.00 & - & - & 1.00 & - & - \\
\hline Boy & - & 0.88 & $0.70-1.10$ & - & 0.90 & $0.73-1.10$ & - \\
\hline
\end{tabular}

${ }^{a}$ Adjusted for all other variables in the model.

${ }^{b}$ NZD, New Zealand dollars. \$70,000 represents average annual household income in region.

Unless otherwise stated, maternal and family data were collected at baseline (third trimester). 
incorporates a range of risk factors without assuming that each has the same impact. It provides a single, generalizable, easily used score for SUDI risk that does not require clinical measurements and can be easily updated as new evidence becomes available through metaanalyses or large studies. Potential applications include its use as a tool for cross-study comparisons (e.g., across different cultures), and for identifying temporal changes (e.g., assessing the impact of public health campaigns).

One similar tool exists, the SIDS risk index score of Conroy and Marks [24] derived from five high risk SUDI sleep practice variables identified from the Confidential Enquiry into Stillbirths and Deaths in Infancy study [25] in a sample of 66 disadvantaged families, the majority of whom were from an ethnic minority group. Bed sharing was not included, and all risk factors were treated as additive, unlike the current study, which has treated the risk factors as multiplicative as the risk estimates were obtained from odds ratios. Two main findings were similar: not being first-born, and higher psychological vulnerability of the mother, were independent predictors of a high SIDS risk index score [24]. Their measure of psychological vulnerability included the EPDS score at 2 months post-partum. In both studies, the EPDS score was treated as a continuum, rather than as a presence or absence of depression defined using clinical cutoffs. Thus, it is the symptoms of depression, rather than clinical depression per se, that the current study and that of Conroy and Marks [24] emphasize as being an important predictor.

Maternal Māori ethnicity was almost statistically significant as a predictor of a high SUDI risk in the unadjusted model $(P=0.053)$, but the association was greatly attenuated after adjusting for other variables (adjusted OR of 1.21 compared to unadjusted OR of 1.79) and was no longer a tendency in the adjusted model. Neither low family income nor household deprivation were independent predictors of SUDI risk.

The prevalence of prone sleeping in our study was low at $1.3 \%$ and $2.8 \%$ of 3 week and 19 week old infants respectively. Nationwide figures for the prevalence of prone sleeping in 3 month old infants before the "Back to Sleep" campaign were $33 \%$ [26], dropping to $3.0 \%$ afterwards [27]. The prevalence of side sleeping nationally was $73 \%$ after the Back to Sleep campaigns [27]. Side sleeping was later recognized as an additional risk factor for SIDS and education to discourage the practice resulted in a fall in the prevalence with local reports of a prevalence of $21 \%$ in 2003 [28]. The present study suggests a further reduction with $12 \%$ and $7.6 \%$ of infants sleeping on their side at 3 weeks and 19 weeks of age respectively. With the reduction in both side sleeping and prone sleeping, the prevalence of supine sleeping here was 90\%, appreciably higher than the $62 \%$ reported in 2003 [29]. Major reasons cited for non-supine sleeping positions are infant preference, infant comfort, and parental fear of choking [30]. However, it is clear that the safe sleep position messages prevail within our community.

The prevalence of mothers smoking during pregnancy in this study (8\%) is slightly lower than the national average of $11 \%$, although the prevalence is significantly higher nationally amongst Māori women (34\%) and in women with lower markers of socioeconomic status [31]. However these groups are not strongly represented in this sample. Meta-analyses published in 1997 [32] and in 2013 [33] concluded that maternal smoking doubles the risk of SIDS. The risks attributed to passive smoking remain unclear, however one study has reported that the risk from postnatal exposure increases with the number of smokers in the household, or with the daily hours the infant is subjected to an environment with cigarette smoke [34]. Encouragingly, in our study, figures for smoking in the car and smoking inside the home were very low.

The advice to not bed share, particularly if the mother smoked in pregnancy or currently, was also being adhered to in this study with only one case of bed sharing in a mother who smoked. However, bed sharing was twice as common at 3 weeks of age as at 7 weeks and older. The reason for this higher rate in younger infants is unknown but may be due to parental choice, maternal sleep needs, or infant feeding practices. A large metaanalysis identified that bed sharing in the absence of maternal smoking was still a risk for SUDI (at 2 weeks, odds ratio $=2.4$ ) but was only significant during the first 8 weeks of life [17]. Furthermore, the risk of bed sharing infants dying in a maternity hospital bed within the first few days of birth has received attention [35]. Room sharing with the baby sleeping in its own cot or bassinette for the first 6 months of life is the recommended practice. Anecdotally, some parents say this is difficult to comply with and Figure 1 illustrates the shift in this practice as the infant gets older, with $68 \%$ room sharing at 3 weeks declining to $38 \%$ at 23 weeks.

Pacifier use at sleep time is associated with a lower SUDI risk through a yet to be determined mechanism [36]. Despite some countries recommending pacifier use for SUDI prevention [37], NZ does not include pacifier use as part of its safe sleep messages. We found pacifier use more than doubled from 3 weeks of age [9.6\%] to 15 weeks, [19\%], similar to the $19 \%$ of 3 month old infants in this region using pacifiers in 2001/2 [29]. This suggests no significant effect of international recommendations on pacifier use in this community, and no broader social effect even though pacifier use is much more common in other countries [32\% to $71 \%$ ] [38].

The suggestion that breastfeeding may be protective against SUDI has been controversial, with many, although not all, studies reporting an association [39]. However, a 
recent meta-analysis suggests that breastfeeding is protective, and that the effect is even stronger when breastfeeding is exclusive [19]. Eighty-nine percent of infants in the current study were breastfed at 2 months of age, compared to $79 \%$ of NZ infants aged approximately 6-9 weeks [40]. Although exclusive breastfeeding is likely to provide greater protection against SUDI [19], we used "any breastfeeding" at 2 months as the marker for protective breastfeeding behaviour. This was because the only estimate available in the literature of the relative risk of SUDI amongst infants who are breastfed was for "any breastfeeding" at 2 months [19].

The strengths of this study include the comprehensive longitudinal dataset, and the availability of earlier data with which to compare and describe changes in child-care practices over time. When exploring independent predictors for SUDI risk scores, this study was able to take into account a wide range of maternal infant and family characteristics. Limitations include, first, the respondents were from areas of low SUDI risk and predominantly Caucasian, thus we don't know how well the score would translate to a study of highrisk infants. Second, the SUDI risk assessment instrument included some unadjusted odds ratios. As data with adjusted odds-ratios for all variables become available from future meta-analyses or high-quality studies, a better estimate of the risk will be possible. Third, the calculation of the total SUDI risk score assumes multiplicative and not additive risks. While this seems appropriate given that the score is based on odds ratios, which are multiplicative in nature, we don't know if this is the case for all factors considered here and it is possible that correlations between risk factors not adjusted for in the analyses found in the literature may lead to very high risk estimates for some families. Again, further calibration of the instrument will be possible when better estimates become available. Finally, missing data limited the calculation of risk scores to 176 of the 209 participants recruited into this arm of the study (84.2\%). Missing alcohol data reduced the number of observations available for that unadjusted model by a further 36 and biases in answering this question may have affected the association reported here. However, as AUDIT-C was not included in the adjusted model, this did not substantially affect the sample size available for that model which was reduced by only $6(3.4 \%)$ due to missing covariates. It seems plausible that missing risk score data would be largely missing at random after conditioning on the covariates included in the adjusted model. However, the presence of missing data increased the widths of the presented confidence intervals and some non-statistically significant predictors (ethnicity and income) have confidence intervals which do not rule out important associations.

\section{Conclusions}

This study has identified groups within the community as priorities for education about safe sleep practices beyond standard care: young mothers, mothers with high parity, mothers with low educational levels, and mothers with symptoms of depression antenatally. The antenatal period is an opportune time to screen for symptoms of depression, providing the chance for early intervention and treatment before birth. We reinforce earlier data suggesting maternal depression is a marker for SUDI risk [23] and within the context of our findings, related to infant care practices. Further research is required to determine whether the findings also apply to infants at high risk of SUDI, particularly in ethnic minority populations, with different cultural infant care practices.

\section{Abbreviations}

AUDIT-C: Alcohol use disorders identification test; EPDS: Edinburgh post-natal depression scale; NZDep2006: New Zealand deprivation index 2006;

PSI: Parental stress index; SIDS: Sudden infant death syndrome; SUDI: Sudden unexpected death in infancy.

\section{Competing interests}

The authors declare that they have no competing interests.

\section{Authors' contributions}

BG prepared the first draft of this manuscript. ARG conducted the statistical analysis and prepared the data for the manuscript. BJT and RT are co-principal investigators on the full study, and together with the other authors, have had significant input into the design and development of this study, and have commented on and edited this manuscript. All authors read and approved the final manuscript.

\section{Acknowledgements}

We thank the families and their infants who participated in this study. We also gratefully acknowledge the research assistance of Catherine Barker, Barbara Churcher, Rhondda Davies, Michelle McGrath, Amelia Needs, Nick Prosser, Megan Somerville, and Bronwyn Thomas. The study was funded by the Health Research Council of New Zealand and the New Zealand Ministry of Health through the Southern District Health Board.

\section{Author details}

'Department of Women's \& Children's Health, University of Otago, Dunedin, New Zealand. ${ }^{2}$ Department of Preventive and Social Medicine, University of Otago, Dunedin, New Zealand. ${ }^{3}$ Department of Human Nutrition, University of Otago, Dunedin, New Zealand. ${ }^{4}$ Department of Medicine, University of Otago, Dunedin, New Zealand.

Received: 17 April 2014 Accepted: 3 October 2014 Published: 13 October 2014

\section{References}

1. Krous HF, Beckwith JB, Byard RW, Rognum TO, Bajanowski T, Corey T, Cutz E, Hanzlick R, Keens TG, Mitchell EA: Sudden infant death syndrome and unclassified sudden infant deaths: a definitional and diagnostic approach. Pediatrics 2004, 114:234-238.

2. Byard RW: Changing infant death rates: diagnostic shift, success story, or both? Forensic Sci Med Pathol 2013, 9:1-2.

3. Dwyer T, Ponsonby AL: SIDS epidemiology and incidence. Pediatr Ann 1995, 24:350-352. 354-6.

4. Mitchell EA, Brunt JM, Everard C: Reduction in mortality from sudden infant death syndrome in New Zealand. Arch Dis Child 1994, 70:291-294.

5. Li D-K, Petitti DB, Willinger M, McMahon R, Odouli R, Vu H, Hoffman HJ: Infant sleeping position and the risk of sudden infant death syndrome in California, 1997-2000. Am J Epidemiol 2003, 157:446-455. 
6. International Society for the Study and Prevention of Perinatal and Infant Death (ISPID): International Infant Mortality Statistics; http://www.ispid.org/ id_statistics.html. Accessed 12 March, 2014.

7. NZ Child and Youth Mortality Review Committee: Fifth report to the Minister of Health: Reporting Mortality 2002-2008; 2009. http://www.hqsc.govt.nz/ assets/CYMRC/Publications/cymrc-5th-report-chp1-sudi.pdf Accessed 12 March, 2014

8. NZ Child and Youth Mortality Review Committee: 9th Data Report 2008 2012; http://www.hqsc.govt.nz/assets/CYMRC/Publications/CYMRC-ninthdata-report-2008-2012.pdf. Accessed 13 March, 2014.

9. Taylor BJ, Heath A-LM, Galland BC, Gray AR, Lawrence JA, Sayers RM, Dale K, Coppell KJ, Taylor RW: Prevention of Overweight in Infancy (POI.nz) study: a randomised controlled trial of sleep, food and activity interventions for preventing overweight from birth. BMC Public Health 2011, 11:942.

10. Ministry of Health: Well Child/Tamariki Ora Services; http://www.health.govt. nz/our-work/life-stages/child-health/well-child-tamariki-ora-services. Accessed 12 March, 2014

11. Cox JL, Holden JM, Sagovsky R: Detection of postnatal depression. Development of the 10-item Edinburgh Postnatal Depression Scale. $\mathrm{Br} J$ Psychiatry 1987, 150:782-786.

12. Murray D, Cox JL: Screening for depression during pregnancy with the Edinburgh Depression Scale (EDDS). J Reprod Infant Psyc 1990, 8:99-107.

13. Loyd BH, Abidin RR: Revision of the parenting stress index. J Pediatr Psychol 1985, 10:169-177.

14. Bush K, Kivlahan DR, McDonell MB, Fihn SD, Bradley KA: The AUDIT alcohol consumption questions (AUDIT-C): an effective brief screening test for problem drinking. Ambulatory Care Quality Improvement Project (ACQUIP). Alcohol use disorders identification test. Arch Intern Med 1998, 158:1789-1795.

15. Salmond C, Crampton P, Atkinson J: NZDep2006 Index of Deprivation User's Manual. Wellington: Department of Public Health, University of Otago; 2007.

16. Gilbert R, Salanti G, Harden M, See S: Infant sleeping position and the sudden infant death syndrome: systematic review of observational studies and historical review of recommendations from 1940 to 2002 Int J Epidemiol 2005, 34:874-887.

17. Carpenter RG, Irgens LM, Blair PS, England PD, Fleming P, Huber J, Jorch G, Schreuder P: Sudden unexplained infant death in 20 regions in Europe: case control study. Lancet 2004, 363:185-191.

18. Vennemann MM, Hense HW, Bajanowski T, Blair PS, Complojer C, Moon RY, Kiechl-Kohlendorfer $\mathrm{U}$ : Bed sharing and the risk of sudden infant death syndrome: can we resolve the debate? J Pediatr 2012, 160:44-48.

19. Hauck FR, Thompson JMD, Tanabe KO, Moon RY, Vennemann MM: Breastfeeding and reduced risk of sudden infant death syndrome: a meta-analysis. Pediatrics 2011, 128:103-110.

20. Hauck FR, Omojokun OO, Siadaty MS: Do pacifiers reduce the risk of sudden infant death syndrome? A meta-analysis. Pediatrics 2005, 116:e716-e723.

21. Robertson E, Grace $S$, Wallington $T$, Stewart DE: Antenatal risk factors for postpartum depression: a synthesis of recent literature. Gen Hosp Psychiatry 2004, 26:289-295.

22. Murray L, Cooper P, Hipwell A: Mental health of parents caring for infants. Arch Womens Ment Health 2003, 6:S71-S77.

23. Mitchell EA, Thompson JM, Stewart AW, Webster ML, Taylor BJ, Hassall IB, Ford RP, Allen EM, Scragg R, Becroft DM: Postnatal depression and SIDS: a prospective study. J Paediatr Child Health 1992, 28:S13-S16.

24. Conroy S, Marks MN: Maternal psychological vulnerability and early infant care in a sample of materially disadvantaged women. J Reprod Infant Psyc 2003, 21:5-22

25. Fleming P, Bacon C, Blair P, Berry PJ: Sudden Unexpected Deaths in Infancy: The CESDI SUDI Studies 1993-1996. London: Stationery Office; 2000.

26. Mitchell EA, Taylor BJ, Ford RPK, Stewart AW, Becroft DMO, Thompson JMD, Scragg R, Hassall IB, Barry DMJ, Allen EM, Roberts AP: Four modifiable and other risk factors for cot death: The New Zealand study. J Paediatr Child Health 1992, 28:S3-S8.

27. Mitchell EA, Tuohy PG, Brunt JM, Thompson JM, Clements MS, Stewart AW Ford RP, Taylor BJ: Risk factors for sudden infant death syndrome following the prevention campaign in New Zealand: a prospective study. Pediatrics 1997, 100:835-840.

28. Mitchell EA, Hutchison L, Stewart AW: The continuing decline in SIDS mortality. Arch Dis Child 2007, 92:625-626.
29. Sayers RM: Prevalence, Predictors and Treatment of Irritability in Infancy, Masters of Health Science thesis. Dunedin, New Zealand: University of Otago; 2004.

30. Chung-Park MS: Knowledge, opinions, and practices of infant sleep position among parents. Mil Med 2012, 177:235-239.

31. Morton SM, Atatoa Carr PE, Bandara DK, Grant CC, Ivory VC, Kingi TK, Liang R, Perese LM, Peterson E, Pryor JE, Reese E, Robinson EM, Schmidt JM, Waldie KE: Growing Up in New Zealand: A longitudinal study of New Zealand Children and their Families. Report 1: Before We Are Born; 2010. http://hdl. handle.net/2292/6120. Accessed March 12, 2014.

32. Anderson HR, Cook DG: Passive smoking and sudden infant death syndrome: review of the epidemiological evidence. Thorax 1997, 52:1003-1009.

33. Zhang K, Wang X: Maternal smoking and increased risk of sudden infant death syndrome: a meta-analysis. Leg Med 2013, 15:115-121.

34. Fleming P, Blair PS: Sudden infant death syndrome and parental smoking. Early Hum Dev 2007, 83:721-725.

35. Poets A, Urschitz MS, Steinfeldt R, Poets CF: Risk factors for early sudden deaths and severe apparent life-threatening events. Arch Dis Child 2012, 97:F395-F397.

36. Mitchell EA, Blair PS, L'Hoir MP: Should pacifiers be recommended to prevent sudden infant death syndrome? Pediatrics 2006, 117:1755-1758.

37. Moon RY: SIDS and other sleep-related infant deaths: expansion of recommendations for a safe infant sleeping environment. Pediatrics 2011, 128:e1341-e1367.

38. Nelson EAS, Yu L-M, Williams S, International Child Care Practices Study Group: International child care practices study: breastfeeding and pacifier use. J Hum Lact 2005, 21:289-295.

39. Young J, Watson K, Ellis L, Raven L: Responding to evidence: breastfeed baby if you can-the sixth public health recommendation to reduce the risk of sudden and unexpected death in infancy. Breastfeed Rev 2012, 20:7-15.

40. Royal New Zealand Plunket Society: Breastfeeding Data. Analysis of 20042009 Data. Wellington: Royal New Zealand Plunket Society; 2010. http://www.plunket.org.nz/news-and-research/research-from-plunket/ plunket-breastfeeding-data-analysis/ Accessed March 12, 2014

doi:10.1186/1471-2431-14-263

Cite this article as: Galland et al:: Safe sleep practices in a New Zealand community and development of a Sudden Unexpected Death in Infancy (SUDI) risk assessment instrument. BMC Pediatrics 2014 14:263.

\section{Submit your next manuscript to BioMed Central and take full advantage of:}

- Convenient online submission

- Thorough peer review

- No space constraints or color figure charges

- Immediate publication on acceptance

- Inclusion in PubMed, CAS, Scopus and Google Scholar

- Research which is freely available for redistribution 